\title{
Thrombotic and Thromboembolic Complications in Patients With Adult Congenital Heart Disease
}

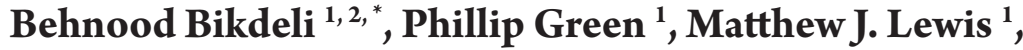 \\ Marlon S. Rosenbaum ${ }^{1}$
}

${ }^{1}$ Division of Cardiology, Department of Medicine, Columbia University Medical Center, New York-Presbyterian Hospital, New York, USA

${ }^{2}$ Center for Outcomes Research and Evaluation, Yale University School of Medicine, New Haven, USA

* Corresponding author: Behnood Bikdeli, Church Street, Suite 200, New Haven, USA.Tel: +203-7645653,E-mail:bb2813@cumc.columbia.edu; behnood.bikde-

DOI: $10.21859 / \mathrm{ijcp}-020201$ li@yale.edu

Submited: 01.10.2017

Accepted: 01.15 .2017

\section{Keywords:}

thrombosis

anticoagulants

Heart Defects, Congenital

(C) 2017. International Journal of

Cardiovascular Practice.

\begin{abstract}
Improved medical and surgical interventions have increased the longevity of patients with congenital heart defects and most such patients live into adulthood. Thrombotic and thromboembolic complications constitute a major cause of mortality and morbidity in patients with adult congenital heart disease (ACHD). Such events include acute coronary syndromes, ischemic stroke (cardioembolic due to thrombus formation in the systemic ventricle, secondary to atrial arrhythmias, or due to paradoxical embolism), and venous thromboembolism. Some thrombotic phenomena are also specific to patients with ACHD, such as those related to Fontan circulation. We provide a succinct overview of thrombotic and thromboembolic complications in patients with ACHD, focusing on stroke and venous thromboembolic events.
\end{abstract}

\section{INTRODUCTION}

Thrombosis and thromboembolism are the most common etiology for acute coronary syndromes, stroke, and venous thromboembolism (VTE) and thereby considered as the leading cause of death worldwide $[1,2]$. With remarkable improvements in medical and surgical care to patients with congenital heart disease, many of them now survive into adulthood [3]. In fact, the number of patients with adult congenital heart disease (ACHD) now exceeds that of the pediatric population. Increased longevity and several biological factors (including increased thrombogenicity) [4, 5], pathophysiological factors (such as increased risk of atrial arrhythmias) [6] and iatrogenic factors (such as Fontan physiology) puts this growing population at increased risk of thrombotic and thromboembolic complications including VTE, stroke, and acute coronary syndromes [7] (Fig 1). Despite commonness of these phenomena, and the growing burden of ACHD, however, there remains a paucity of data on epidemiology, prognostication and management approach for these patients.

The significance of such thrombotic complications also led to release of a scientific statement by the American heart association (AHA) on thrombosis prevention and treatment in patients with congenital heart disease [8]. Although patent foramen ovale (PFO) with or without precedent stroke is an important clinical scenario, we opted to exclude that population from the current review. Further, acute coronary syndrome in patients with $\mathrm{ACHD}$ is an emerging topic with potential distinct association with certain syndromes [9]. In the current mini-review, we chose to focus on broad aspects of thrombosis and thromboembolic risk related to VTE and stroke in patients with ACHD. We highlight the areas that require urgent research attention.

\section{ISCHEMIC STROKE}

Acute ischemic stroke, most often of embolic nature, may occur in several patient subsets with ACHD [12]. Embolic stroke in such patients may have various etiologies including thrombus formation and embolization from a dysfunctional systemic ventricle, left atrial appendage thrombus formation in the setting of atrial fibrillation (AF)/ flutter, or paradoxical embolism via a right-to-left shunt.

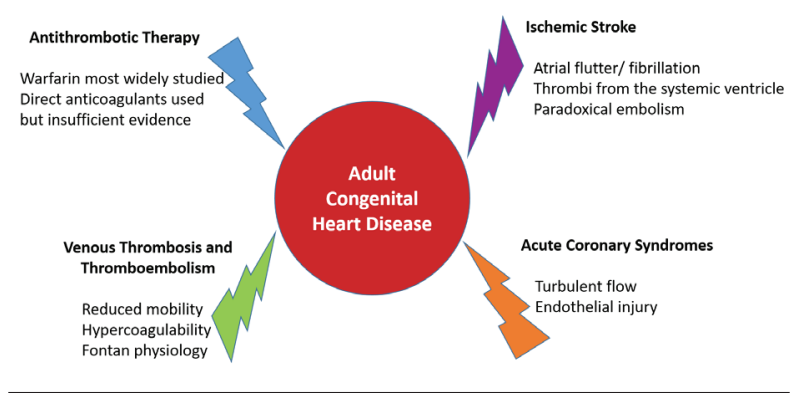

Figure 1: Major Thrombotic and Thromboembolic Presentations in Patients with Adult Congenital Heart Disease 
Table 1: Select Set of Recommendations From the AHA Scientific Statement on Prevention and Treatment of Thrombosis in Patients With Congenital Heart Disease ${ }^{a}$

\begin{tabular}{|c|c|c|}
\hline Setting & AHA Recommendation & Comment \\
\hline $\begin{array}{l}\text { Congenital Heart Dis- } \\
\text { ease and AF or Atrial } \\
\text { Flutter }\end{array}$ & Warfarin therapy is recommended & $\begin{array}{l}\text { NOACs have been empirically used but not formally } \\
\text { tested in randomized trials. } \\
\text { (We need additional studies to better identify the } \\
\text { subgroups who are at highest risk of thromboembolic } \\
\text { events.) }\end{array}$ \\
\hline Fontan Circulation & $\begin{array}{l}\text { Warfarin is recommended if patients have doc- } \\
\text { umented atrial thrombus, atrial arrhythmia, or a } \\
\text { thromboembolic episode. }\end{array}$ & $\begin{array}{l}\text { A study of } 111 \text { patients with Fontan surgery did not show } \\
\text { a difference in the rate of thromboembolic events among } \\
\text { patients randomized to warfarin compared with aspirin } \\
\text { [10]. A subsequent analysis from the study, however, } \\
\text { showed that patients achieving target INR, or those } \\
\text { receiving aspirin, had lower thromboembolic events com- } \\
\text { pared with those would had a subtherapeutic INR [11]. } \\
\text { Better risk profiling of these patients and identification of } \\
\text { optimal antithrombotic strategies are required. }\end{array}$ \\
\hline
\end{tabular}

There are subsets of ACHD that are proposed to have an elevated risk of thrombosis, including those with cyanotic defects. For example, although a prior study of cyanotic patients had not revealed evidence of clinical stroke in 112 participants [13], another study of 162 patients with cyanotic congenital heart disease reported cerebrovascular events in $13.6 \%$ of patients [14]. More recently, a study of 98 patients with cyanotic congenital heart disease from Sweden reported imaging evidence of cerebral infarction in nearly half of participants. It is important to note that many of these neurologic events were diagnosed by imaging and were not associated with symptoms or clinical sequelae [15].

Despite the clinical rationale for increased thrombosis risk in many ACHD patients, in the absence of large studies specific to patients with ACHD, the evidence for antithrombotic therapy is extrapolated from data in broader cohort of patients. Generally, antiplatelets agents are employed for secondary prevention in acute cryptogenic stroke while anticoagulation is utilized for treatment of systemic ventricular thrombosis or paradoxical embolism from VTE. Of note, while anticoagulation is used in the setting of AF/Aflutter for patients with $\mathrm{ACHD}$, the $\mathrm{CHA}_{2} \mathrm{DS}_{2}$-VASc score has not been specifically validated in this population. In one study, among patients with ACHD and atrial arrhythmias, congenital heart disease complexity, but not the CHA2DS2-VASc score, was predictive of subsequent thromboembolic events [16]. As such, multicenter research delineating thrombosis risk in the setting of AF/Aflutter in the ACHD population is warranted.

\section{VENOUS THROMBOEMBOLISM (VTE)}

Patients with ACHD may have specific factors that increase the risk of VTE [12]. In addition to thrombophilias that may be seen in some subsets of patients with ACHD, VTE risk may also be related to limited mobility, particularly in patients with class III or IV symptoms. Additionally, VTE in patients with ACHD could be due to specific hemodynamic and flow patterns, such as those with Fontan physiology. Patients with ACHD and Fontan physiology are a special subset, with increased risk of stroke, as well as embolic events from the right-sided structures, causing PE [17]. Studies have suggested an increased risk of thrombotic events and death in patients who do not receive any antithrombotics [18]. Based on these, the consensus recommendation is to consider anticoagulation for patients with Fontan physiology, particularly if they have coexisting atrial arrhythmias, a history of prior embolic events, or evidence of poor venous flow [17]. However, choice of treatment varies across institutions with anticoagulation and aspirin both frequently used. While warfarin is the most frequently employed anticoagulant there is emerging data regarding the use of non-vitamin Koral anticoagulants in the adult Fontan patients [19, 20]. Randomized trials are necessary to determine both the choice of agent and the appropriate timing of anticoagulation.

\section{CONCLUSIONS}

In addition to hemodynamic, arrhythmic, and infectious complications, patients with ACHD are at significant risk for thrombotic and thromboembolic conditions. Clinicians should be mindful of thrombotic complication in patients with $\mathrm{ACDH}$ and consider appropriate diagnostic and therapeutic approaches. Further research is required to identify the highest-risk subgroups, and to test strategies that could safely mitigate the thrombotic/thromboembolic risk.

\section{FUNDING}

Authors declared there is no funding or support.

\section{REFERENCES}

1. Wendelboe AM, Raskob GE. Global Burden of Thrombosis: Epidemiologic Aspects. Circ Res. 2016;118(9):1340-7. DOI: 10.1161/ CIRCRESAHA.115.306841 PMID: 27126645

2. Bikdeli B, Gupta A, Mody P, Lampropulos JF, Dharmarajan K. Most important outcomes research papers on anticoagulation for cardiovascular disease. Circ Cardiovasc Qual Outcomes. 2012;5(5):e6574. DOI: 10.1161/CIRCOUTCOMES.112.968701 PMID: 22991352

3. Marelli AJ, Mackie AS, Ionescu-Ittu R, Rahme E, Pilote L. Congenital heart disease in the general population: changing prevalence and age distribution. Circulation. 2007;115(2):163-72. DOI: $10.1161 /$ CIRCULATIONAHA.106.627224 PMID: 17210844

4. Emani S, Zurakowski D, Baird CW, Pigula FA, Trenor C, 3rd, Emani SM. Hypercoagulability markers predict thrombosis in single ventricle neonates undergoing cardiac surgery. Ann Thorac Surg. 
2013;96(2):651-6. DOI: 10.1016/j.athoracsur.2013.04.061 PMID: $\underline{23809731}$

5. Kajimoto H, Nakazawa M, Murasaki K, Mori Y, Tanoue K, Kasanuki $\mathrm{H}$, et al. Increased thrombogenesity in patients with cyanotic congenital heart disease. Circ J. 2007;71(6):948-53. PMID: 17526995

6. Walsh EP, Cecchin F. Arrhythmias in adult patients with congenital heart disease. Circulation. 2007;115(4):534-45. DOI: 10.1161/ CIRCULATIONAHA.105.592410 PMID: 17261672

7. Monagle P. Thrombosis: congenital heart disease and thrombosis: what do we know? Nat Rev Cardiol. 2014;11(3):132-4. DOI: 10.1038/nrcardio.2013.217 PMID: 24395044

8. Giglia TM, Massicotte MP, Tweddell JS, Barst RJ, Bauman M, Erickson $\mathrm{CC}$, et al. Prevention and treatment of thrombosis in pediatric and congenital heart disease: a scientific statement from the American Heart Association. Circulation. 2013;128(24):2622-703. DOI: 10.1161/01.cir.0000436140.77832.7a PMID: 24226806

9. Yalonetsky S, Horlick EM, Osten MD, Benson LN, Oechslin EN, Silversides CK. Clinical characteristics of coronary artery disease in adults with congenital heart defects. Int J Cardiol. 2013;164(2):21720. DOI: $10.1016 /$ j.ijcard.2011.07.021 PMID: 21807422

10. Monagle P, Cochrane A, Roberts R, Manlhiot C, Weintraub R, Szechtman B, et al. A multicenter, randomized trial comparing heparin/warfarin and acetylsalicylic acid as primary thromboprophylaxis for 2 years after the Fontan procedure in children. J Am Coll Cardiol. 2011;58(6):645-51. DOI: 10.1016/j.jacc.2011.01.061 PMID: 21798429

11. McCrindle BW, Manlhiot C, Cochrane A, Roberts R, Hughes M, Szechtman B, et al. Factors associated with thrombotic complications after the Fontan procedure: a secondary analysis of a multicenter, randomized trial of primary thromboprophylaxis for 2 years after the Fontan procedure. J Am Coll Cardiol. 2013;61(3):346-53. DOI: 10.1016/j.jacc.2012.08.1023 PMID: 23246393

12. Giannakoulas G, Boutsikou M. The Gordian knot of thromboembo- lism in congenital heart disease. Heart. 2015;101(19):1523-4. DOI: 10.1136/heartjnl-2015-308045 PMID: 26194592

13. Perloff JK, Marelli AJ, Miner PD. Risk of stroke in adults with cyanotic congenital heart disease. Circulation. 1993;87(6):1954-9. PMID: 8504509

14. Ammash N, Warnes CA. Cerebrovascular events in adult patients with cyanotic congenital heart disease. J Am Coll Cardiol. 1996;28(3):768-72. PMID: 8772770

15. Jensen AS, Idorn L, Thomsen C, von der Recke P, Mortensen J, Sorensen KE, et al. Prevalence of cerebral and pulmonary thrombosis in patients with cyanotic congenital heart disease. Heart. 2015;101(19):1540-6. DOI: 10.1136/heartjnl-2015-307657 PMID: 26048878

16. Khairy P, Aboulhosn J, Broberg CS, Cohen S, Cook S, Dore A, et al. Thromboprophylaxis for atrial arrhythmias in congenital heart disease: A multicenter study. Int J Cardiol. 2016;223:729-35. DOI 10.1016/j.ijcard.2016.08.223 PMID: 27573597

17. Balling G. Fontan Anticoagulation: A Never-Ending Debate? J Am Coll Cardiol. 2016;68(12):1320-2. DOI: 10.1016/j. jacc.2016.06.050 PMID: 27634124

18. Khairy P, Fernandes SM, Mayer JE, Jr., Triedman JK, Walsh EP, Lock JE, et al. Long-term survival, modes of death, and predictors of mortality in patients with Fontan surgery. Circulation. 2008;117(1):85 92. DOI: 10.1161/CIRCULATIONAHA.107.738559 PMID: $\underline{18071068}$

19. Pujol C, Niesert AC, Engelhardt A, Schoen P, Kusmenkov E, Pittrow $D$, et al. Usefulness of Direct Oral Anticoagulants in Adult Congenital Heart Disease. Am J Cardiol. 2016;117(3):450-5. DOI: 10.1016/j.amjcard.2015.10.062 PMID: 26725103

20. Cheng K, Harrogate S, Orchard E. The Use of Novel Oral Anticoagulants in Adult Congenital Heart Disease: A Single Center Experience. Am J Cardiol. 2016;117(2):312-3. DOI: 10.1016/j.amjcard.2015.11.002 PMID: 26679425 